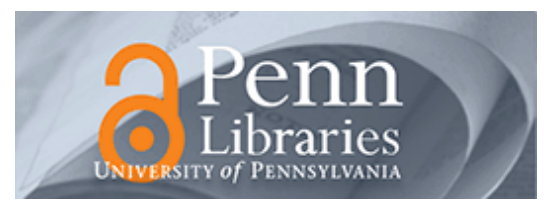

University of Pennsylvania

ScholarlyCommons

Marketing Papers

Wharton Faculty Research

8-2007

\title{
Where Consumers Diverge from Others: Identity Signaling and Product Domains
}

Jonah A. Berger

University of Pennsylvania

Chip Heath

Follow this and additional works at: https://repository.upenn.edu/marketing_papers

Part of the Marketing Commons

Recommended Citation

Berger, J. A., \& Heath, C. (2007). Where Consumers Diverge from Others: Identity Signaling and Product Domains. Journal of Consumer Research, 34 (2), 121-134. http://dx.doi.org/10.1086/519142

This paper is posted at ScholarlyCommons. https://repository.upenn.edu/marketing_papers/196

For more information, please contact repository@pobox.upenn.edu. 


\title{
Where Consumers Diverge from Others: Identity Signaling and Product Domains
}

\begin{abstract}
We propose that consumers often make choices that diverge from those of others to ensure that they effectively communicate desired identities. Consistent with this identity-signaling perspective, four studies illustrate that consumers are more likely to diverge from majorities, or members of other social groups, in product domains that are seen as symbolic of identity (e.g., music or hairstyles, rather than backpacks or stereos). In identity domains, participants avoided options preferred by majorities and abandoned preferences shared with majorities. The social group associated with a product influenced choice more in identity domains and when a given product was framed as identity relevant. People diverge, in part, to avoid communicating undesired identities.
\end{abstract}

\section{Keywords}

social influence, social contagion, identity, reference groups

Disciplines

Business | Marketing 


\title{
Where Consumers Diverge from Others: Identity Signaling and Product Domains
}

\author{
JONAH BERGER \\ CHIP HEATH*
}

\begin{abstract}
We propose that consumers often make choices that diverge from those of others to ensure that they effectively communicate desired identities. Consistent with this identity-signaling perspective, four studies illustrate that consumers are more likely to diverge from majorities, or members of other social groups, in product domains that are seen as symbolic of identity (e.g., music or hairstyles, rather than backpacks or stereos). In identity domains, participants avoided options preferred by majorities and abandoned preferences shared with majorities. The social group associated with a product influenced choice more in identity domains and when a given product was framed as identity relevant. People diverge, in part, to avoid communicating undesired identities.
\end{abstract}

$\mathrm{K}$ ids often want to separate themselves from their parents, and jocks want to separate themselves from geeks. Manhattanites stopped wearing mesh trucker hats when the bridge-and-tunnel crowd adopted them (Barker 2004), and Shanghai residents avoid purchasing Volkswagen Santanas because they are a favorite first car among the suburban nouveaux riches (Wonacott 2004). People often diverge from others in their choices, adopting tastes that distinguish them from other people and abandoning tastes if too many people, or the "wrong" types of people, adopt them.

Prior research demonstrates that consumers have a drive to differentiate themselves from others (Snyder and Fromkin 1980; also see Ariely and Levav 2000), and these individualdrive theories have focused mostly on stable individual differences in needs for uniqueness (Snyder and Fromkin 1977; see also Lynn and Harris 1997; Tian, Bearden, and Hunter

*Jonah Berger is an assistant professor of marketing at the Wharton School, University of Pennsylvania, 700 Jon M. Huntsman Hall, 3730 Walnut, Philadelphia, PA 19104 (jberger@wharton.upenn.edu). Chip Heath is a professor of organizational behavior at the Stanford University Graduate School of Business, Stanford, CA 94305 (Heath_Chip@gsb.stanford.edu). This article is based on a portion of the first author's doctoral dissertation, conducted under the supervision of the second author and Itamar Simonson. The authors would like to thank Jennifer Aaker, Jim Bettman, Jonathan Levav, Wendy Liu, Noah Mark, Cynthia Pickett, Baba Shiv, Itamar Simonson, and Christian Wheeler for their helpful comments. In addition, the authors would like to thank John Deighton, the associate editor, and three reviewers for constructive suggestions that greatly strengthened the article.

John Deighton served as editor and Ann McGill served as associate editor for this article.

Electronically published June 13, 2007
2001) or the consequences of temporary situations that lead individuals to feel undifferentiated (Byrne and Griffitt 1969). They suggest that individuals with higher needs for uniqueness prefer unique products (Tian et al. 2001; Tian and McKenzie 2001) or that when situational pressures make individuals feel overly similar, people seek ways of achieving a sense of difference (Snyder and Fromkin 1980).

But across individuals and independent of temporary situational pressures, people tend to diverge more in certain product domains than others. Consider the following pilot study we conducted. Fifty-one undergraduates at Stanford University chose options in 19 preference domains (e.g., power tools, stereos, hairstyles, and favorite CD). In each domain, they were told that $65 \%$ of other students owned option A, $25 \%$ owned option B, and $10 \%$ owned option C. They were then asked which option they would choose. Clearly, option $\mathrm{C}$ is the choice that establishes the greatest divergence from others because it is shared by the fewest number of people. Yet as figure 1 indicates, preferences for option $\mathrm{C}$ differed substantially across domains (repeatedmeasures ANOVA; $F(18,50)=15.98, p=.001)$. People were more likely to diverge by selecting option $\mathrm{C}$ in domains such as favorite CD $(67 \%)$ or hairstyle $(27 \%)$ than in domains such as dish soap (6\%) or power tools (10\%). Prior work on individual drives for differentiation tells us a lot about who is more likely to prefer unique products or when people might be more likely to prefer them. But these approaches have less to say about where people diverge or why across individuals people diverge more in certain domains. Why might people diverge more in certain domains of social life, and what does this tell us about the mechanisms that motivate divergence?

This article proposes a new, more social approach to un- 
FIGURE 1

DIVERGENCE IN TASTE SELECTION, SORTED BY GREATEST DIVERGENCE (PILOT STUDY)

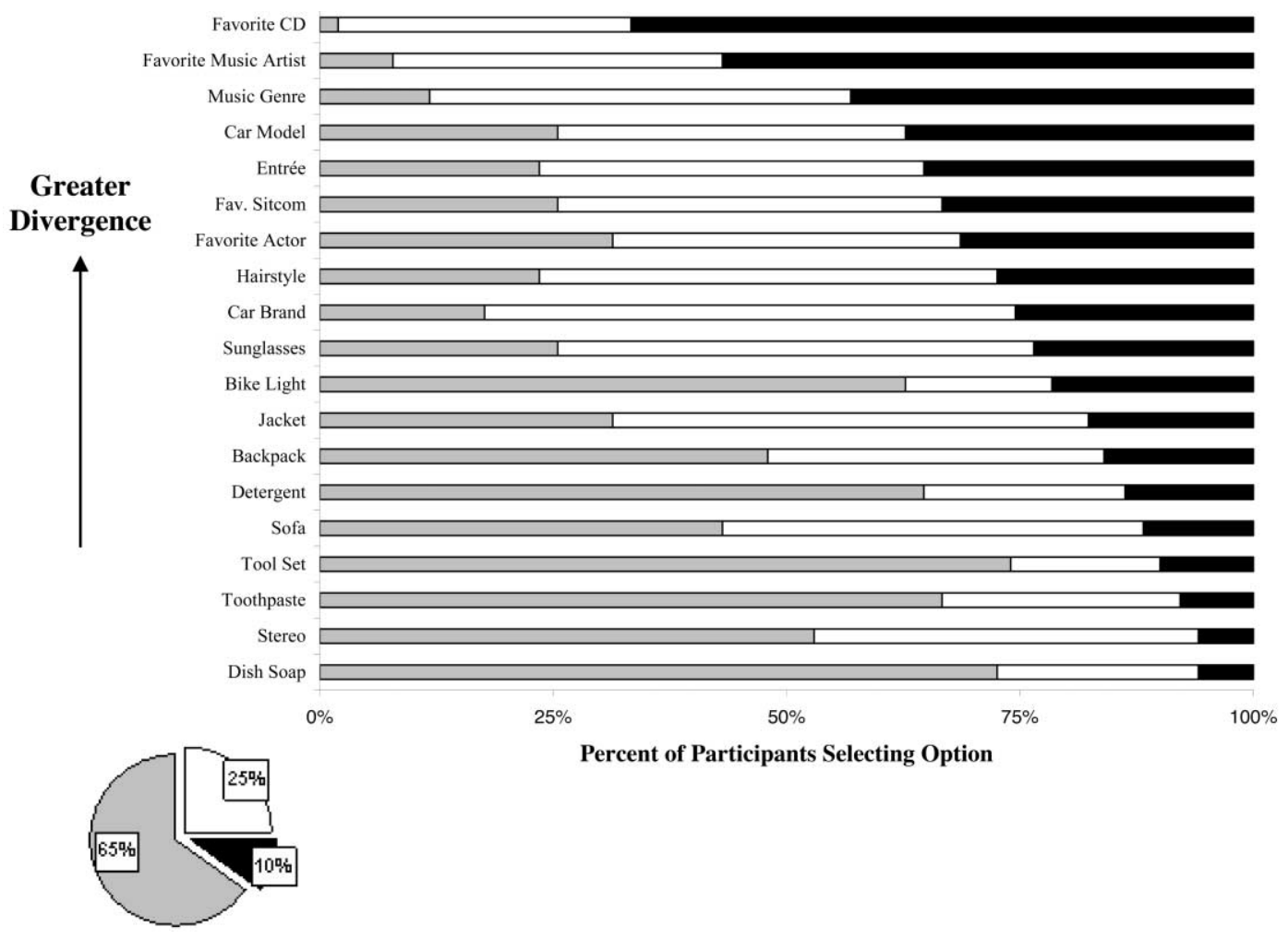

derstanding why people diverge; we suggest that people often diverge to communicate or signal their identity to others. Rather than focusing on individual drives to be different, or individual differences, our identity-signaling model focuses on the social process of communication. We test this approach by examining whether it can explain why divergence varies by domain. If divergence is driven by identity-signaling concerns, then people should be more likely to diverge in domains others use to infer identity. Before presenting four studies that test our theory, we first review literature on drives for differentiation and then outline our identity-signaling approach.

\section{INDIVIDUAL DRIVES FOR DIFFERENTIATION}

Scholars across the social sciences have argued that people have a drive to be different (Brewer 1991; Snyder and Fromkin 1980; see Vignoles, Chryssochoou, and Breakwell [2000] for a review). The most well-cited drive approach in consumer behavior and psychology, the uniqueness literature (Fromkin 1970; Snyder and Fromkin 1980), contends that individuals experience a negative emotional reaction when they feel overly similar to others. Uniqueness research has focused on temporary situational pressures and stable individual differences. When people are temporarily made to feel overly similar to others, they behave in ways that allow them to feel different (e.g., being creative [Fromkin 1968] or misremembering levels of similarity [Byrne and Griffitt 1969]). People with higher stable needs for uniqueness also prefer greater differentiation from others on a more consistent basis (Snyder and Fromkin 1977; Tian et al. 2001), and individuals care more about being unique in domains that they find personally important (Campbell 1986; Kernis 1984). A car enthusiast, for instance, should care more about having a unique roadster than would a coin collector.

These approaches, however, are mostly silent on the issue of why divergence would vary by domain. Personal importance, for example, suggests that coin collectors and bottle-cap collectors both care more about being unique in their own particular personally important hobby domains, but it cannot explain why sports and theater and cooking enthusiasts would all prefer more distinction in their hairstyles and music choices as opposed to their dish soap and power tools. Similarly, if individuals prefer to diverge more in certain domains, this cannot be explained by a universal drive for difference, by stable individual differences in this drive, or by temporary fluctuations in this drive. The fact that divergence happens more often in certain domainsacross individuals - suggests that something beyond just internal drives may be causing divergence. 


\section{DIVERGENCE TO AVOID SIGNALING UNDESIRED IDENTITIES}

We suggest that people often diverge to ensure that others make desired identity inferences about them. Rather than focusing on internal drives, this social approach focuses on the reception of meaning.

People's tastes - the products they buy, attitudes they profess, and preferences they hold - can act as signals of identity, communicating useful information to others (Wernerfelt 1990). People buy products for not only what they do but also what they symbolize (Levy 1959). Consumers use products to construct and express desired identities (Belk 1988; Escalas and Bettman 2003, 2005; Kleine, Kleine, and Kernan 1993), and people infer aspects about others (e.g., identities and other preferences) based on their purchase decisions (Calder and Burnkrant 1977; for overviews, see Belk, Bahn, and Mayer 1982; Holman 1981). Tastes can act as markers of social groups (Douglas and Isherwood 1978) and signal a user's other preferences (Solomon 1988; Solomon and Assael 1987). One might posit that a Volvo driver is a Democrat and that a long-haired blonde guy who says "gnarly" is a surfer.

Tastes can signal identity, but the particular identity that people infer from another's choice depends on the set of people who share the taste. Building on McCracken's (1988) theory of meaning movement, tastes communicate identity through their association with the groups or "types" of individuals that use them (also see Muniz and O'Guinn 2001). If lots of tough people ride Harley motorcycles, then Harleys may come to signal a rugged identity. But adoption by outsiders can change this signal; if suburban accountants start riding Harleys in an attempt to seem tough, the meaning of the taste may change, either becoming diluted and losing its meaning or signaling different characteristics altogether (wannabe tough guys). Similarly, tastes that are held by a majority will not provide clear signals of any one particular identity. Not only will majority tastes not signal any group identity cleanly, but if holding a majority taste does communicate an identity, the identity signaled may be that one is a "conformist." Wearing an indie band T-shirt before the band makes it big may signal hipster status, but wearing the same shirt once everyone owns it may signal that the person just follows trends (Thornton 1996), which may produce negative social impressions (see Pronin, Berger, and Molouki 2007).

We suggest that people may diverge to avoid others making undesired identity inferences about them. By converging together and choosing the same thing in a given domain, similar individuals can imbue a taste with meaning, leading it to signal desired characteristics (e.g., group membership). But if that taste is also held or adopted by outsiders, it may lose its ability to signal desired characteristics effectively. Consequently, people may diverge in their choices to distinguish themselves from members of other social groups (Bourdieu 1979/1984; Hebdige 1987; Simmel 1904/1957). They may avoid selecting tastes that are held by out-groups or a majority and abandon previously held tastes that are adopted by out-group members.

Our identity-signaling approach to divergence differs from existing notions of anticonformity (Nail, MacDonald, and Levy 2000) because it also involves convergence with the in-group. People do not just differentiate themselves from out-groups in whatever idiosyncratic way they happen to choose; indeed, to signal identity clearly, people do not want to be the only one holding a given taste. Identity signaling thus involves both processes of convergence and differentiation. Similar individuals converge together to imbue signals with meaning but diverge from members of other social groups so that they can avoid signaling undesired characteristics (see Berger, Heath, and Ho [2007] for an indepth model).

\section{DIVERGENCE AND DOMAINS}

One way to test our identity-signaling model of divergence is to examine how strongly people prefer to diverge across different domains; if divergence is driven by identitysignaling concerns, as we suggest, then people should be more likely to diverge in domains that others use to infer identity.

While any product could theoretically be used to infer identity, people seem to use certain types of taste domains more than others (Belk 1981). For example, when students were asked to select cues that would aid in making inferences about other students, most selected either clothing or academic courses (Burroughs, Drews, and Hallman 1991). Some products are more easily able to communicate things about their users (Escalas and Bettman 2005), and research on attitude functions contrasts symbolic products (e.g., a school sweatshirt) with those that are more instrumental (e.g., a stereo [Shavitt 1990]; see also Katz 1960). Compared to more utilitarian products, when people were asked to describe the type of person who uses a given product, identity-relevant products elicited more dispositional information about another person (Shavitt and Nelson 1999). Thus, people seem to be more likely to make identity inferences about others when taste domains are seen as symbolic of identity.

Our identity-signaling approach predicts that people should be more likely to diverge from others in domains that others use to infer identity. We argue that the number of people who hold a taste, and the social group to which they belong, will have a greater impact on divergence in identity-relevant domains.

H1: Individuals will be more likely to diverge from a majority in domains that others use to infer identity.

H2: The identity of the other people who share one's tastes will have a greater influence on divergence in domains others use to infer identity.

Different individuals may diverge more in the specific do- 
mains they find personally important (e.g., coins or bottle caps), but across individuals people should be more likely to diverge in domains that most people see as identity relevant.

Four studies test our hypotheses. Studies 1 and 2 test the first hypothesis, examining whether people are more likely to select tastes that diverge from a majority (study 1) and abandon tastes that they learn are shared with a majority (study 2) in domains that others use to infer identity. Study 2 also examines the interplay of individual drives for differentiation and identity signaling. Studies 3 and 4 test the second hypothesis. Study 3 examines whether people care about not only the number of others who share their identityrelevant tastes but also the particular social group to which those others belong. Study 4 uses a priming manipulation to see whether the group associated with the taste has a greater influence on divergence when the same domain is framed as more identity relevant.

\section{STUDY 1: DIVERGENCE IN SELECTING TASTES}

Study 1 examined whether people are more likely to select tastes held by fewer others in domains that others use to infer people's identity. A national Internet sample completed the choice task from the pilot study presented earlier. In a number of choice domains, respondents chose either the option preferred by $65 \%$ of others (A), $25 \%$ of others (B), or $10 \%$ of others $(\mathrm{C})$. This three-option structure allows us to separate identity signaling from majority avoidance. If people just want to avoid the majority, they could choose either option B or C, but if they want to signal identity, they should prefer option $\mathrm{C}$ because it is more likely to be able to communicate specific identities. We also asked two separate groups of raters to rate each domain on how much it was used to either express or infer identity. If signals are socially sent and received, then people should use the same domains to send signals (express identity) that others use to receive them (infer identity).

The default prediction based on informational influence (Deutsch and Gerard 1955), and conformity more generally (Asch 1951), would be that people should conform, converging to the option chosen by the most others. The choices of others provide information, and when people do not know what to choose they may use others' choices to answer the question, "Will I like it?" In the context of study 1 then, this literature would predict that, across domains, people should select the option preferred by the majority (option A). Instead, we predict that people would prefer to diverge from others in domains that people use to express and infer identities.

We also tested whether divergence could just be explained by whether products are publicly visible. Some research, though it has not focused on divergence directly, has highlighted differences between private and public consumption. People choose more variety in public settings than private ones (Ratner and Kahn 2002), and reference group influence is generally greater for products consumed publicly (e.g., cars and suits as opposed to mattresses; Bearden and Etzel 1982). Combined, these results might predict that divergence depends on whether the domain is publicly visible (also see Tian et al. 2001). Consequently, we had a separate set of respondents who also rated how publicly visible one's choices are in a given domain.

\section{Method}

Participants. Two hundred and one respondents (mean age $=38$ ) from a broad Web survey database that includes participants from across the United States completed a "Preference Survey" in exchange for a $\$ 5$ gift certificate.

Option Choice. Participants completed the same choice task used in the pilot study. They were shown the same 19 different preference domains and chose one of three options in each domain. In the stereo domain, for example, participants could choose the stereo chosen by $65 \%$ of others, $25 \%$ of others, or $10 \%$ of others.

Domain Ratings. Separate groups of participants rated the same domains either on self-expression ("how much it contributes to self-expression-i.e., a person's ability to express their identity"; $N=20$ ) or identity inference making ("how much people use it to make inferences about others-i.e., people think they know a lot about a person based on their choice in this domain"; $N=20$ ). Consistent with our identity-signaling perspective, the ratings of self-expression and identity inference making were highly correlated $(r=.95)$, so we averaged them to form an index of domain identity relevance. Within each set of respondents there was also a high degree of consensus ( $\alpha$ 's $>.91$ ), suggesting that across individuals there is a great deal of agreement about which domains are identity relevant. A separate group also rated each domain on its public visibility $(N=32)$. All ratings were on seven-point scales.

\section{Results}

As predicted, people were more likely to diverge in domains others use to infer identity. We first analyzed the data by product domain, averaging choices for each domain across individuals. An ordinary least squares (OLS) regression predicting choice of the $10 \%$ option based on domain identity relevance found that people were more likely to choose the $10 \%$ option when the domain was identity relevant $(\beta=.64, p=.003)$. Respondents were more likely to select option $\mathrm{C}$ in domains such as hairstyle and favorite music artist than dish soap or bike light (fig. 2). Identical results were found when the data were analyzed on the subject level using a repeated-measures ANOVA and a median split on domain identity relevance; $31 \%$ of participants preferred option $\mathrm{C}$ in identity-relevant domains, but only $16 \%$ preferred it in domains that were less identity relevant $(F(1,201)=88.00, p<.001)$.

Returning to the domain level, an OLS regression pre- 
FIGURE 2

DIVERGENCE IN TASTE SELECTION SORTED BY IDENTITY RELEVANCE OF THE PRODUCT DOMAIN (STUDY 1)

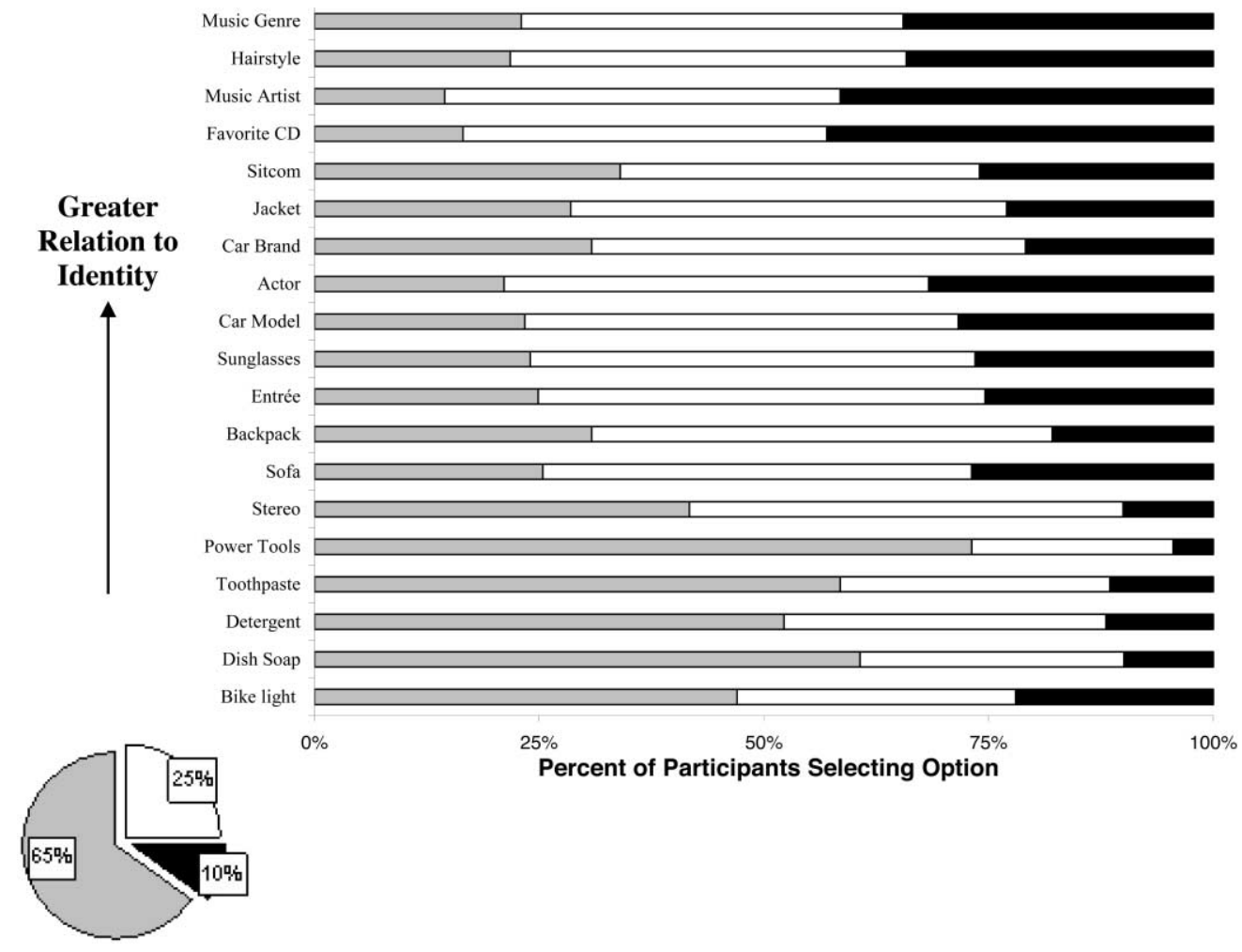

dicting preference for option $\mathrm{C}$ based solely on public visibility found the effect to be nonsignificant $(\beta=.05, p>$ .38). However, a multiple regression using both identity relevance and public visibility found that the percentage of people selecting option $\mathrm{C}$ increased when the domain was identity relevant $(\beta=.88, p=.001)$ but actually decreased in domains that were publicly visible $(\beta=-.43, p=$ .05). A multiple discriminant analysis found similar results, while also helping to resolve this seeming contradiction with prior work. This analysis found that people were more likely to select the moderate-sized group ( $25 \%$; option B) in public domains, suggesting that visibility drives people toward options that are neither too popular nor too unique.

\section{Discussion}

Results of study 1 support our identity-signaling account of divergence; people are more likely to choose options that are held by a small minority in domains that are relevant to identity (supporting hypothesis 1). Consistent with our focus on the social nature of identity signaling, even though our Internet sample came from a range of demographic backgrounds, participants exhibited strong agreement about which domains were identity relevant. Further separate sets of raters agreed that similar domains are used to express and infer identity. The results underscore the social nature of divergence; individuals do not establish difference from majorities in every domain or any random domain-they do so more in domains where others look for signals about their identity.

The results also suggest that when choice is publicly visible, people prefer associating with moderately sized groups. Public consumption often involves self-presentation, leading people to choose in ways that present the self positively (Ratner and Kahn 2002). Consequently, people may avoid both the majority and the minority options when choice is public to avoid being seen as either conformist or weird.

Study 1 suggests that when selecting tastes, people diverge more in identity-relevant domains, but it involves a questionnaire manipulation that might lack social immediacy. Study 2 places people in a social context where they anticipate revealing their preferences to others. Furthermore, it investigates a particularly strong form of divergence-whether people will abandon tastes they once preferred when they learn that a majority shares them. Finally, we measure need for uniqueness (NFU) to examine the interplay between individual drives and identity signaling.

\section{STUDY 2: DIVERGENCE THROUGH TASTE ABANDONMENT}

The results of study 1 are consistent with an identitysignaling account of divergence, but one could argue that 
they merely reflect informational influence. Under conditions of uncertainty, we often rely on others for information about whether we will like something (Campbell and Fairey 1989; Deutsch and Gerard 1955). This might lead people to converge with the majority in functional, nonidentity domains (e.g., bike lights or laundry detergent), but people may believe that they will dislike things preferred by majorities in identity-relevant domains. Consequently, because the only thing study 1 participants knew about a product was the percentage of others that liked it, one could argue that they diverged from majorities in identity-relevant domains due to beliefs about preference heterogeneity rather than concerns of identity signaling.

To more explicitly rule out this account, study 2 uses actual products with which participants should already be familiar (e.g., popular car brands) and examines product abandonment. Abandonment is a particularly stringent test of any informational account because it explores situations where consumers abandon a preference that they have previously expressed. When consumers already know and like a product, their uncertainty is low, and it is difficult for an informational perspective to explain why learning about another's preferences should cause an individual to diverge.

In this study, participants choose between familiar options in a number of product domains. Later, through an elaborate cover story, we exposed some participants to data suggesting the signal value of their preference was low because it was shared with a majority of others (majority-preference condition). We then remeasured their preferences to examine whether they would abandon prior preferences. Our identitysignaling account predicts that people should be more likely to abandon tastes in domains others use to infer identity.

We also included a control condition where participants had their preferences remeasured with no exposure to information about others' preferences. Any taste change in this condition should be due to random preference change over time, and participants should not show greater divergence in identity-relevant domains.

To examine how abandonment is influenced by individual drives for differentiation, we also measured each participant's need for uniqueness. People with high needs for differentiation may be more willing to abandon their preferences when they discover their preferences are shared with a majority of others, but work on individual differences does not predict in which domains people will be more or less likely to diverge.

\section{Pretest-Effect of Sharing Preference with a Majority}

Before turning to our main study, we first examined whether, as suggested, learning that one's preferences are shared with a majority changes people's ability to signal identity effectively. Twenty students were asked to imagine that their preference was shared by either eight (or two) of 10 other students from their school and make a binary choice of whether or not they thought that their preference was shared by people outside their social type ("Do you think that these people are all the same type of person, e.g., same social group/type, as you?"). As expected, students who were told that a majority of other students (eight of 10) shared their preference were more likely to believe the preference was shared by people with different identities $\left(M_{\mathrm{maj}}=70 \%\right.$ vs. $\left.M_{\mathrm{min}}=20 \% ; \chi^{2}(20)=5.05, p<.03\right)$. This supports the notion that tastes held by majorities do not provide clear identity signals.

\section{Method}

Time 1-Taste Elicitation. In the first stage of the experiment, 40 Stanford University students completed a "Preference Survey" as part of a larger testing session for which they were paid \$20. They were presented with 25 preference domains (e.g., car brand, musical artist, and toothpaste), each of which included five options, and were asked to "circle the option you like the best from each of the choice sets." In the music domain, for instance, participants chose their preferred artist from five popular artists: Dave Mathews, Outkast, Usher, Cake, and Alicia Keys. Eight of the domains, varying in identity relevance, were used as target domains in the next portion of the study.

Time 2-Manipulation. Two to 3 weeks later, participants were contacted by a different experimenter and returned to the lab in small groups (two to seven people) for an ostensibly unrelated study about how people talk about their preferences. Participants expected to complete two short surveys and discuss their preferences on the second.

In the lab, participants entered a room full of cubicles where a research assistant (RA) was already seated, surrounded by stacks of paper and visibly entering data by marking a large sheet of paper. The experimenter started participants on an unrelated task and, before leaving, asked the RA how the data entry was going. She replied that it was slow and that there were a lot more data left to enter. The experimenter apologized, noting that another person was supposed to help but had canceled. He then left the room.

A minute later he returned, asking the RA if she had more copies of the main study packet. She replied that there might be none left. The experimenter then left for a moment and returned to say he would need to go make copies. He apologized to the participants, who at this point had finished the unrelated survey, and asked the RA if there was anything else the participants could do while he made copies. After thinking, she replied that she could really use help entering data. The experimenter then asked the participants if they would be willing to enter data while he made copies: all said yes. He gave each participant a data entry sheet and a small stack of "previous surveys," explained that the surveys explored what was popular among students, and asked participants to help tally the results. He then thanked participants for their help and left to make copies.

The data each participant tallied were carefully calibrated to suggest that certain preferences of theirs were shared by 
others. Each participant received data from 10 previous respondents, each of whom had chosen among five options in 12 different taste domains (eight target domains plus four fillers). Responses suggested that a majority of "previous respondents" had chosen the option the participant chose at time 1 (the percentage was lower in filler domains to avoid suspicion). The degree of convergence varied across target domains (from $60 \%$ to $80 \%$ ) but was equivalent across domains that were more and less identity relevant. Instances of convergence were interspersed so that no previous respondent made all the same choices as the participant.

After allowing participants time to tally the data, the experimenter returned with the copies. He thanked the participants and asked them to total and circle the number of previous respondents who had chosen each alternative in each domain. He then collected the sheets and handed out the "actual survey," explaining that after completion, the group would get together to discuss their choices.

Each of the eight target domains appeared on a separate sheet of paper, alternating identity- and non-identity-relevant domains, and participants were asked to "circle the option you like the best from each of the choice sets on the next few pages." They then came together as a group and discussed their preferences. Finally, participants completed the Need for Uniqueness Scale (Snyder and Fromkin 1977) and were debriefed. No participant reported awareness of a link between the response tallies and the main survey.

Control Condition. A separate set of 20 respondents, drawn from the same population, went through the same procedure as participants in the main study, but they were not exposed to information regarding the choices of others at time 2 .

\section{Results}

To create the dependent variable, we summed the number of times a participant chose a different option at time 2 than they did at time 1. To explore how much divergence was driven by personality factors and identity signaling, we performed median splits on both domain identity relevance (using domain ratings from study 1) and NFU. We then examined the number of times a participant diverged using a 2 (domain identity relevance: high vs. low) $\times 2$ (condition: majority preference vs. control) $\times 2$ (NFU: high vs. low) mixed ANOVA.

We predict a domain identity relevance $\times$ condition interaction: participants in the majority-preference condition, relative to the control condition, should be more likely to abandon their previous choices in domains that are more identity relevant. In addition, individual differences in NFU do not predict where people will diverge, but they should predict who is more likely to diverge from others. People with high needs for uniqueness should be more likely to diverge when they learn that their preferences are shared with a majority but should be no more likely to diverge in the control condition because they did not learn that their preferences were shared. Thus, we expect an NFU $\times$ con- dition interaction. Finally, because people need to signal identity, regardless of their NFU, we predict that individual differences in NFU should not moderate the domain identity relevance $\times$ condition interaction. People should diverge more in identity-relevant domains, regardless of the degree of differentiation they personally prefer.

Consistent with hypothesis 1 , learning that one's preferences were shared with a majority of others led people to diverge, but more so in identity-relevant domains; participants in the majority-preference condition abandoned more preferences in domains that were relevant to identity $\left(M_{\text {id rel }}=1.11\right.$ vs. $M_{\text {lsidrel }}=0.72 ; F(1,56)=6.71, p=$ $.01)$. As predicted, the analysis also revealed a significant domain identity relevance $\times$ condition interaction $(F(1,56)=10.23, p=.002$; see fig. 3A). Comparing conditions, participants in the majority-preference condition abandoned a greater number of preferences in identityrelevant domains $(M=1.11)$ than did control-condition participants $(M=0.72 ; F(1,56)=5.69, p=.02)$. This reinforces the notion that learning that one's preferences were shared by a majority, rather than random taste change over time, was what led participants to abandon tastes in identity-relevant domains. Consistent with an individual differences approach, there was also marginal NFU $\times$ condition interaction $(F(1,56)=2.80, p=.10$; see fig. $3 B)$. High NFU participants diverged more than low NFU participants in the majority-preference condition $\left(M_{\mathrm{hiNFU}}=\right.$ 1.12 vs. $\left.M_{\mathrm{loNFU}}=0.71 ; F(1,56)=4.97, p=.03\right)$. NFU did not influence divergence in the control condition where participants merely made the same choice at two points in time $(F<0.5)$. There were no other significant main effects or interactions $(p$ 's $>.30)$.

\section{Discussion}

Supporting an identity-signaling account, people again diverged more in domains others use to infer identity. Upon learning that their preferences were shared by a majority, and anticipating having a public group discussion of their preferences, people were more likely to abandon previously held preferences in identity-relevant domains (supporting hypothesis 1).

This pattern cannot be explained by people forgetting their previous choices or some sort of random preference change over time: participants in the control condition who were not exposed to the preferences of others did not show greater divergence in identity-relevant domains. Furthermore, compared to these control participants, majority-preference participants showed greater divergence in identity-relevant domains. It is also difficult to explain this pattern using an information account based on the perceived distribution of others' preferences. The fact that others like something should provide little additional information in cases where people already know what they like.

Alternatively, one could suggest that people were more indifferent between the choices available in identity-relevant domains and, because they had less to lose by switching to their second favorite option, were more willing to diverge 
FIGURE 3

A: DIVERGENCE AS A FUNCTION OF CONDITION AND PRODUCT DOMAIN IDENTITY-RELEVANCE (STUDY 2)

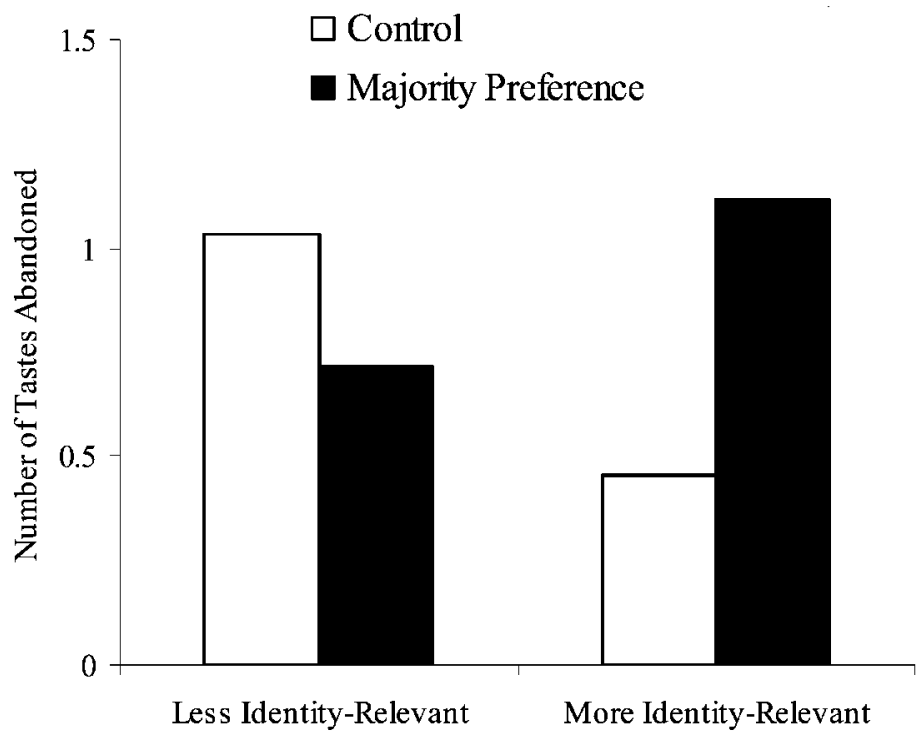

Domains

\section{B: EFFECT OF CONDITION AND NEED FOR UNIQUENESS ON DIVERGENCE}

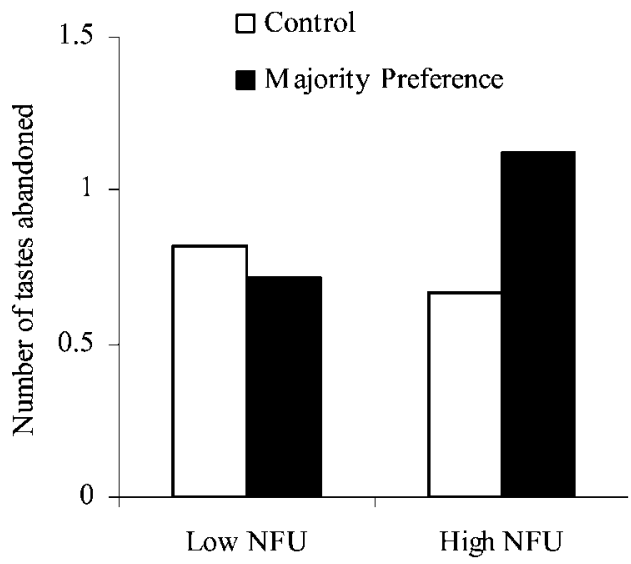

in these domains. But separate analysis showed that abandoning tastes was equally costly across domains. A separate set of people $(N=20)$ ranked the options and then rated how much they liked each one $(1=$ not at all; $7=$ a great deal). Raters liked their first choice significantly more than their second choice $(M=5.70$ vs. $5.20 ; F(1,19)=39.48$, $p<.001)$, but the size of this difference in preference did not differ across identity and nonidentity domains $(M=$ 0.51 vs. $0.49 ; F<0.5)$.

This study also allowed us to examine the interplay of domains and individual drives for differentiation. Consistent
C: EFFECT OF DOMAIN IDENTITYRELEVANCE AND NEED FOR UNIQUENESS ON DIVERGENCE

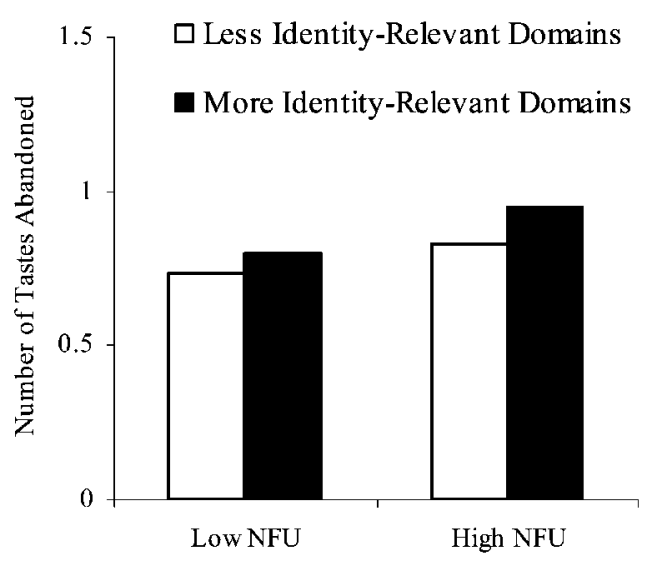

with prior research, individual differences in NFU did a good job identifying people who were more likely to diverge; upon learning their preferences were shared with a majority of others, people with higher needs for uniqueness abandoned more tastes. But to understand where people will diverge, we need to consider which domains are used to signal identities. Across levels of NFU, people were more likely to diverge in identity-relevant domains (see fig. 3C).

The first two studies demonstrate that individuals are more likely to diverge in domains people use to express and infer identity. But someone might accept that divergence varies 
by domain without accepting our explanation that identity concerns drive the process. Perhaps individuals just want to be more distinctive in certain domains, regardless of whether it signals that they possess a particular identity. If identity signaling underlies domain differences in divergence, we ought to see stronger results when we make identities more explicit. Study 3 does this.

\section{STUDY 3: MODERATING INFLUENCE OF GROUP ASSOCIATION}

Study 3 tests whether identity signaling drives divergence by examining whether divergence depends on the identity of the group associated with a taste. Prior research indicates that consumers' choices are often influenced by reference groups (Bearden and Etzel 1982; Moschis 1976; Stafford 1966), and people may conform to the choices of similar others due to information or a need to belong, avoid punishment, or express identity (Deutsch and Gerard 1955; Park and Lessig 1977). Consumers may also avoid options that are linked to certain out-groups to avoid being associated with them (Berger and Heath 2007; Englis and Solomon 1995; White and Dahl 2006). Building on these findings, study 3 examines how the identity of the group associated with a taste interacts with whether the particular taste domain is used to infer identity.

We asked participants to consider a group that they liked but whom they considered either similar to or different from themselves. We wanted to move beyond simply showing that people diverge from a taste if it is associated with a group they dislike. Divergence from a disliked group is consistent with identity signaling, but it is also consistent with many other theories (e.g., that we avoid things with negative associations). Participants were then given a modified version of the choice task from study 1 . In addition to getting information about the overall distribution of preferences (i.e., 65/100 like option A, 25/100 option B, and $10 / 100$ option C), they were also given information about the distribution of preferences for members of the group they listed (see fig. 4). This information suggested that although option A received the largest absolute level of choice from the group they named, option $\mathrm{C}$ was most diagnostic of the listed group.

If individuals just prefer being more distinctive in certain domains, then they should be more likely to select option $\mathrm{C}$ in identity-relevant domains, regardless of the particular group with which it is associated (main effect of domain). An information account based on the perceived distribution of others' preferences would predict that people should always select option A in less identity-relevant domains (because people should assume preferences are relatively homogeneous in these domains) and also select option $\mathrm{A}$ in identity-relevant domains when the listed group is similar (because this option is preferred by the largest number of similar others). Instead, based on identity signaling, we predict that people will be more likely to select option $\mathrm{C}$ in identity-relevant domains, but this effect should be mod-
FIGURE 4

DIAGRAM GIVEN TO PARTICIPANTS ILLUSTRATING WHO LIKED DIFFERENT OPTIONS (STUDY 3)

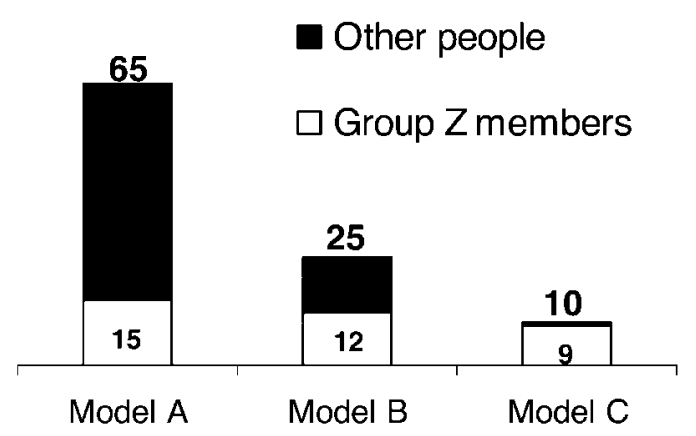

erated by the identity associated with the taste; people should be more likely to select option $\mathrm{C}$ when it is diagnostic of others who have a similar, as opposed to dissimilar, social identity (Berger and Heath 2007).

\section{Method}

One hundred and twenty-three students and staff members at Stanford University were randomly assigned to a condition and completed a choice survey as part of a group of studies for which they received $\$ 20$. Participants wrote in either an in-group or out-group, depending on condition (adapted from Escalas and Bettman 2005). Specifically, participants in the in-group (out-group) condition were asked: "Please write in the name of a social group that you like and consider yourself similar to/belong to (quite dissimilar to/different from). This group should be a tightly knit group, consisting of individuals who are very similar to one another." For the rest of the survey, this group was called group Z.

Participants chose one of three options (A, B, or C) in various preference domains (e.g., dish soap, stereos, or hairstyles; 19 in all). They were told that out of 100 people, 65 preferred option A (15 of which were group $\mathrm{Z}$ members), 25 preferred option B (12 of which were group $\mathrm{Z}$ members), and 10 preferred option $C$ (nine of which were group $Z$ members; see fig. 4). Accordingly, option A was the most popular option, and option $\mathrm{C}$, the least popular, both overall and among group $\mathrm{Z}$ members. But although option $\mathrm{C}$ was the most distinctive option, it was also the option most associated with group $\mathrm{Z}$.

Finally, participants completed a number of ancillary measures. They rated how much they would learn about a person (e.g., that person's preferences, beliefs, and attitudes) if they found out that the person belonged to group $\mathrm{Z}$ or did not belong to the group $(1=$ nothing at all; $7=$ a great deal). They also rated how much they liked the people in group $Z(-3=$ do not like at all; $3=$ like a great deal $)$, their similarity to members of group Z ( $1=$ extremely dissimilar; 7 = extremely similar), and how much they identified with group $\mathrm{Z}(1=$ very little; $7=$ a great deal $)$. 


\section{Results}

Preliminary Analyses. Participants listed a variety of social groups ranging from athletes and choral groups to various fraternities and sororities. Comparing the conditions, participants in the in-group condition thought that they were more similar to group $\mathrm{Z}\left(M_{\text {in }}=4.85\right.$ vs. $M_{\text {out }}=3.06$; $t(101)=7.71, p<.001)$ and were more identified with group $\mathrm{Z}\left(M_{\text {in }}=4.98\right.$ vs. $M_{\text {out }}=3.18 ; t(101)=6.27, p<$ .001). Importantly, however, there was no significant difference in liking of the groups listed across conditions $(t(101)=1.60, p>.11)$.

In addition, consistent with our argument that tastes do not create a strong signal when they are held by too many people, people thought that they knew more about a person's preferences, attitudes, and beliefs if that person was a member of a small group (here, group $\mathrm{Z}, M=5.17$ ) rather than a member of the majority (not a group $\mathrm{Z}$ member, $M=$ 2.78; $t(102)=5.28, p<.001)$.

Main Analyses. We have three predictions. First, consistent with hypothesis 1 , people should diverge more from majorities (i.e., select option $\mathrm{C}$ more frequently) in identity-relevant domains. Second, consistent with literature on reference groups, because option $\mathrm{C}$ is most diagnostic of group Z, participants should be more likely to select option $\mathrm{C}$ if group $\mathrm{Z}$ is their in-group rather than their out-group. Finally, consistent with hypothesis 2 , we expect an interaction; the identity of group $\mathrm{Z}$ should have greater influence on selection of option $\mathrm{C}$ in identity-relevant domains. People should be especially likely to select option $\mathrm{C}$ in domains that people use to signal identity and when the option is most diagnostic of their in-group, so it is an identity signal that they want to send. A median split was performed on domain identity relevance and a 2 (group association: in-group vs. out-group) $\times 2$ (domain identity relevance: high vs. low) mixed ANOVA examined choice likelihood of option $\mathrm{C}$.

As predicted, there were main effects of both domain identity relevance $(F(1,101)=30.32, p=.001)$ and group association $(F(1,101)=11.50, p=.001$; see fig. 5). Participants were more likely to select option $\mathrm{C}$ in identityrelevant domains $(M=31.8 \%$ vs. $17.7 \%)$ and when that option was associated with an in-group $(M=31.1 \%$ vs. $18.4 \%$ ). Most important, there was also a significant domain identity relevance $\times$ group association interaction $(F(1,101)=4.37, p=.04)$. People were more likely to select option $\mathrm{C}$ when it was associated with the in-group, even in less identity-relevant domains $(F(1,101)=4.01$, $p=.05)$, but this tendency was magnified in identity-relevant domains $(F(1,101)=11.71, p<.001)$.

\section{Discussion}

Study 3 provides further evidence that divergence is driven by identity signaling. Consistent with hypothesis 2 , the identity of the other taste holders had a greater influence on divergence in identity-relevant domains. In identity-rel-
FIGURE 5
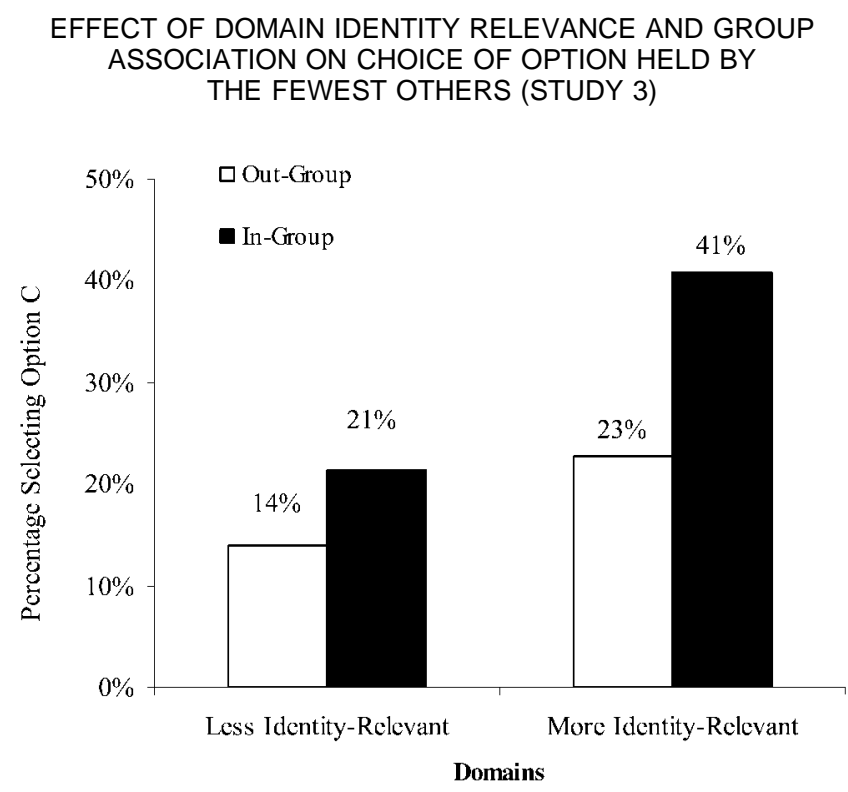

evant domains, people chose the minority option when it signaled their identity, but they avoided the minority option when it signaled an out-group identity. People were less influenced by taste-holder identity in domains that were less relevant to identity. An information account cannot explain why more people in the in-group condition would choose the option that best signals group identity (option C, 38.9\%) rather than the option preferred by the highest number of in-group members (option A, 29.8\%; see table 1).

It is likely that these results were driven by two separate identity concerns: the desire to signal a particular identity and the desire to avoid signaling that one is a conformist. Consistent with this interpretation, participants in the outgroup condition showed increased selection of option B in identity-relevant domains (see table 1); this allowed them to avoid both the conformist option A and the option that was most diagnostic of another social group (C).

To provide further evidence that identity concerns are driving divergence, our final study takes one product and uses a priming task to make that product appear more identity relevant or more functional. When primed to think about products as identity relevant, people should care more about the identities of the others who also use that product.

\section{STUDY 4: PRIMING IDENTITY RELEVANCE}

If divergence is driven by identity signaling, then divergence should differ depending on whether people see a particular domain as a good avenue to signal identity. The first three studies have treated domain identity relevance as a static construct, but the same domain may seem more or less identity relevant depending on the context. Clothes, for instance, may seem less identity relevant when thinking 
TABLE 1

OPTION SELECTION BY IDENTITY RELEVANCE OF THE PRODUCT DOMAIN AND GROUP ASSOCIATION CONDITION: STUDY 3 (\%)

\begin{tabular}{|c|c|c|c|c|c|c|}
\hline & \multicolumn{3}{|c|}{ In-group } & \multicolumn{3}{|c|}{ Out-group } \\
\hline & $65 \%$ (option A) & $25 \%$ (option B) & $10 \%$ (option C) & $65 \%$ (option A) & $25 \%$ (option B) & $10 \%$ (option C) \\
\hline Less identity relevant & 54.3 & 25.0 & 20.7 & 66.7 & 20.9 & 12.5 \\
\hline More identity relevant & 29.8 & 31.3 & 38.9 & 44.9 & 34.0 & 21.1 \\
\hline
\end{tabular}

about what to wear when cleaning the garden as opposed to going out on the town. Study 4 tests this possibility by considering one product and using a prime to encourage participants to frame the product as more functional or more identity relevant. Participants first wrote about products they own that either express their identity or provide functional benefits. Then, in an ostensibly unrelated task, they were asked to evaluate a new digital music player after reading information that suggested the player was evaluated positively by either a dissimilar social group or just people in general.

Based on hypothesis 2, we predict that the others' identity will play a greater role in divergence when the product is framed as identity relevant as opposed to functional. Further, identity-primed individuals should show decreased liking for the product when it is associated with dissimilar others (Berger and Heath 2007).

\section{Method}

Forty-four undergraduates at Stanford University were randomly assigned to condition and completed two surveys as part of a larger study for which they received \$8. Participants first completed a "Product Ownership Survey" in which they wrote a few sentences about products they own. They were told that the experimenters were "interested in the way people describe the products they own," and in the identity-relevant (functional) condition, they read: "Sometimes people choose things based on how well that thing expresses their identity (they perform a specific function). In the space below, please write 5-7 sentences about something or things you own that you bought that expresses who you are to the people around you (for the functional benefits it provides). Also write about why you decided to purchase that particular type/brand. For instance, some people may buy a specific pair of sunglasses because they feel it expresses the type of person they are (toothpaste because it freshens breath and does a good job of fighting cavities)."

After the writing task, participants were asked to complete an ostensibly unrelated survey on "New Product Testing." They were told that the experimenter was interested in "your attitudes towards a new digital music player that Real Music Inc. is considering putting on the market," and they were given both general product information (e.g., memory size and product slogan) as well as "results of some recent focus group testing." Conditions differed only in the identity of focus group participants who liked the device. Specifically, people in the control (dissimilar) condition read: "The device was recently tested among a group of individuals (35-44year-old business executives) and $77 \%$ of participants (business executives) reported that they could see themselves using the eMuse device. In addition, $69 \%$ of participants (business executives) suggested the device fit what they were looking for." Business executives were chosen as the dissimilar out-group because pretest data found that student participants did not dislike this group (average liking $=$ .22 on $\mathrm{a}-3=$ very negative and $3=$ very positive scale) but saw them as dissimilar (average similarity $=2.4$ on a $1=$ not very similar and $7=$ very similar scale).

Participants then completed a number of dependent measures regarding their attitudes toward the device. They were asked how much they liked the device $(1=$ do not like at all; $10=$ like a great deal) and asked to rate their attitude toward the device on a number of dimensions (bad-good, negative-positive, and unfavorable-favorable).

\section{Results}

The four device evaluation items were highly correlated $(\alpha=.97)$ and averaged to form a product evaluation index. Participants scores were analyzed using a 2 (prime: functional vs. identity relevant) $\times 2$ (others' identity: control vs. dissimilar) ANOVA.

The analysis revealed marginal main effects of both prime $(F(1,43)=3.00, p=.09)$ and others' identity $(F(1,43)=$ $2.87, p=.10$; see fig. 6$)$. More important, there was a predicted prime $\times$ others' identity interaction $(F(1,43)=$ $4.26, p=.04)$. Specifically, participants' evaluations were influenced by the identity of other potential users when they were primed to think of products as identity relevant $\left(M_{\text {exec }}=4.85\right.$ vs. $\left.M_{\text {gen }}=3.06 ; F(1,43)=5.86, p<.02\right)$ but not when they were primed to think about products serving a functional purpose $(M=8.13$ vs. $7.82 ; F<1)$.

\section{Discussion}

The results of study 4 reinforce the notion that divergence across domains is driven, at least in part, by identity signaling. Consistent with hypothesis 2 , the identity of the people associated with the taste played a greater role in when a product was seen as identity relevant. When people were primed to think about products that serve a functional purpose, product evaluations were not affected by the identity of other potential users. But when people were primed to think of products as expressing identity, the identity of other potential users had an effect; participants liked the product 


\section{FIGURE 6}

INFLUENCE OF PRIME AND IDENTITY ASSOCIATED WITH PRODUCT ON PRODUCT EVALUATION (STUDY 4)

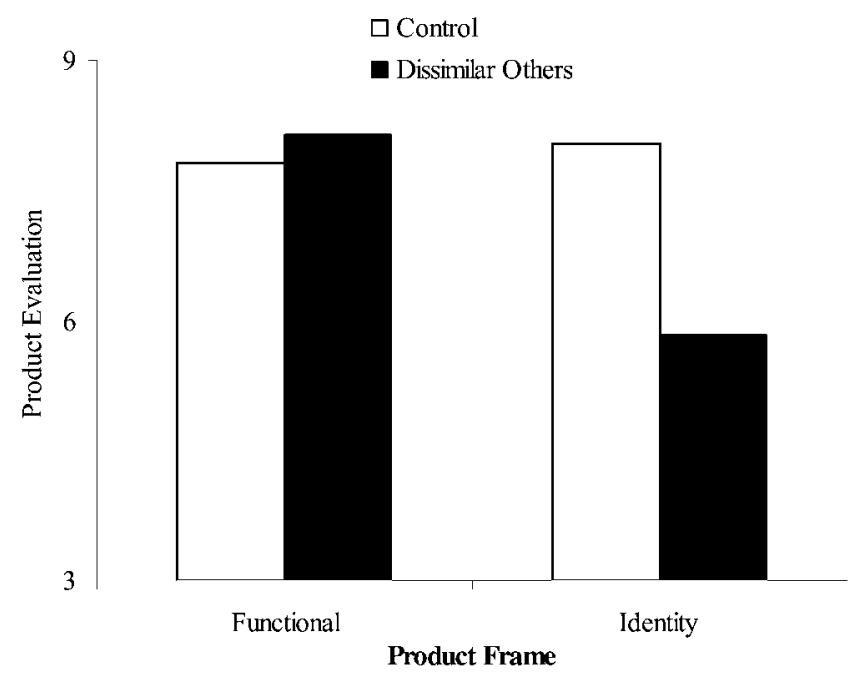

less when it was associated with a liked group that had a different identity.

\section{GENERAL DISCUSSION}

In this article, we propose a new approach to differentiation that helps to explain where consumers diverge. Rather than focusing on individual drives to be unique, we take a more social approach, focusing on how choices can signal particular identities to the broader social world. People use symbolic domains to make identity inferences about others, but the particular identities that are inferred depend on who else holds the taste. Consequently, who else holds the taste-both the size of the group of taste holders and the social group to which they belong-will have a greater influence on divergence in domains that others use to infer identity.

Four studies supported our identity-signaling perspective, illustrating that consumers are more likely to diverge in domains that others use to infer identity. Supporting hypothesis 1 , people were more likely to diverge from majorities in domains others use to infer identity (studies 1 and 2). Supporting hypothesis 2 , the identity of the other people who share a taste had a greater impact on divergence in identity-relevant domains (studies 3 and 4). These effects were shown both when divergence was measured through the tastes that people selected (studies 1 and 3) and when people abandoned tastes that they had already chosen (study 2). Greater divergence in identity-relevant domains was even shown using the same domain, by framing it either as more functional or more identity relevant (study 4).

Our identity-signaling perspective builds on research suggesting that people want to feel differentiated by arguing that people also care about communicating specific, desired identities. The uniqueness literature suggests that whenever people feel overly undifferentiated, whether due to temporary situational pressures or stable individual differences, they will take steps to reduce this negative emotional state. Identity signaling adds to this perspective by suggesting that consumers also want to communicate particular social identities; identity signaling is based on consumers' desire to signal a specific identity, not just an unusual one.

This article has identified a new, identity-based mechanism that drives divergence, but we do not want to claim that all divergence is driven by identity signaling. Hipsters may all wear the same style of jacket, allowing them to signal their type (as we predict), but they are likely to select different colors (as predicted by the uniqueness literature), allowing them to feel somewhat unique relative to others of their type. The contribution of our studies is to suggest that across individuals, certain domains are more identity relevant, and consumers are more likely to diverge in these domains.

\section{Extensions and Directions for Future Research}

Certain characteristics seem to make taste domains particularly well suited for inferring identity. Prior research suggests that people infer identity from product choices that are publicly visible and made from a large choice set and take time or effort to make (Belk 1981; Shavitt 1990). In other research we have conducted, we add another factor to this list: people are more likely to see domains as identity relevant whenever choice is based less on function (Berger et al. 2007). Based on psychological discounting (Kelley 1973), people should find it easier to attribute someone's choice to individual characteristics when the choice does not produce obvious functional benefits. Backpacks and pens have an obvious functional component that is missing from music, indeed the very afunctionality of music makes it a stronger signal of identity. Afunctionality also illuminates which product attributes are more likely to serve as signals. Clothes are functional, but their color and style are less functional. A spike-laden motorcycle jacket is a good signal of identity because a plain brown one is equally warm. Individual tastes can also identify themselves as identity relevant by strategically reducing functionality. A cap is more of a fashion statement when the bill is turned backward; sunglasses are more of a fashion statement indoors, where they make it harder to see.

Although certain domains tend to be used in identity inference making, that does not mean that people cannot express identity in other domains. These identity signals are probably less likely to be picked up by the population at large, but they may be helpful in coordinating with other members of a highly sophisticated in-group. Buying a very high-end stove may not be a good way of signaling identity to most people because most people do not look to stoves for identity signals. But the high-end stove may be a good way to signal to interior designers or kitchenophiles. Even in functional domains, extremes-extreme knowledge, purchasing an extremely costly item, or attending to fine de- 
tails-may be good signals because they separate sophisticates from the general population.

Identity signaling also helps us understand why tastes formerly considered "cool" die out (also see Gladwell [2000] for a popular treatment). Tastes can become cool because they are associated with social groups others consider cool. But if outsiders, or the mainstream more broadly, adopt these tastes, they may lose their ability to signal a cool identity. Catchphrases such as "radical" or "bling" were considered cool when they were localized to certain social groups (e.g., surfers or hip-hop artists), but once they are adopted by grandmothers or appear in ads for bagel bites, they are no longer a good signal of identity. Consequently, original taste holders may diverge and move on to a new identity signal, and the process will repeat itself (see Berger et al. [2007] for a model of this process). Identity signaling thus helps us better understand product life cycles (Golder and Tellis 2004) and the process by which tastes spread (Rogers 1983).

Our identity-signaling perspective provides insight into not only where people will diverge but also where they will conform. Conformity is one of the most basic principles underlying social behavior, yet while individuals want to be both similar and different (Brewer 1991; Snyder and Fromkin 1980), little research explains where conformity versus divergence will occur. We suggest that both the taste domain and the group membership of the other people who are engaging in the behavior play a role (Berger 2007). In nonidentity-relevant domains, people should conform to the preferences of others, regardless of their social group. In identity-relevant domains, however, group membership should have a larger influence; people should converge with similar others to imbue tastes with meaning, but they should diverge from the signals favored by other groups. Understanding where consumers diverge provides a window into important social processes of divergence, conformity, and identity.

\section{REFERENCES}

Ariely, Dan and Jonathan Levav (2000), "Sequential Choice in Group Settings: Taking the Road Less Traveled and Less Enjoyed," Journal of Consumer Research, 27 (December), 279-90.

Asch, Solomon E. (1951), "Effects of Group Pressure upon the Modifications and Distortion of Judgments," in Groups, Leadership, and Men, ed. Harold Guetzkow, Pittsburgh: Carnegie.

Barker, Olivia (2004), "Everything Is So 5 Minutes Ago," USA Today, January 26, $1 \mathrm{D}$.

Bearden, William O. and Michael J. Etzel (1982), "Reference Group Influence on Product and Brand Purchase Decisions," Journal of Consumer Research, 9 (September), 183-94.

Belk, Russell W. (1981), "Determinants of Consumption Cue Utilization in Impression Formation: An Associational Deviation and Experimental Verification," in Advances in Consumer Research, Vol. 8, ed. Kent Monroe, Ann Arbor, MI: Association for Consumer Research.

(1988), "Possessions and the Extended Self," Journal of Consumer Research, 15 (September), 139-67.
Belk, Russell W., Kenneth D. Bahn, and Robert N. Mayer (1982), "Developmental Recognition of Consumption Symbolism," Journal of Consumer Research, 9 (June), 4-17.

Berger, Jonah (2007), "Conformity versus Divergence: The Role of Identity-Signaling in Responses to Social Influence," working paper, Marketing Department, Stanford University.

Berger, Jonah and Chip Heath (2007), "From Whom Do People Diverge? Out-Group Similarity, Identity-Signaling, and Divergence," working paper, Marketing Department, Stanford University.

Berger, Jonah, Chip Heath, and Ben Ho (2007), "Divergence in Cultural Practices: Tastes as Signals of Identity," working paper, Marketing Department, Stanford University.

Bourdieu, Pierre (1979/1984), Distinction: A Social Critique of the Judgment of Taste, trans. Richard Nice, Cambridge, MA: Harvard University Press.

Brewer, Marilynn (1991), "The Social Self: On Being the Same and Different at the Same Time," Personality and Social Psychology Bulletin, 17 (5), 475-82.

Burroughs, W. Jeffrey, Dave R. Drews, and William K. Hallman (1991), "Predicting Personality from Personal Possessions: A Self-Presentational Analysis," Journal of Social Behavior and Personality, 6 (6), 147-63.

Byrne, Donn and William Griffith (1969), "Similarity and Awareness of Similarity of Personality Characteristic Determinants of Attraction," Journal of Experimental Research in Personality, 3 (3), 179-86.

Calder, Bobby J. and Robert E. Burnkrant (1977), "Interpersonal Influence on Consumer Behavior: An Attribution Theory Approach," Journal of Consumer Research, 4 (June), 29-38.

Campbell, Jennifer D. (1986), "Similarity and Uniqueness: The Effects of Attribute Type, Relevance, and Individual Differences in Self-Esteem and Depression," Journal of Personality and Social Psychology, 50 (2), 281-94.

Campbell, Jennifer D. and Patricia J. Fairey (1989), "Informational and Normative Routes to Conformity: The Effect of Faction Size as a Function of Norm Extremity and Attention to the Stimulus," Journal of Personality and Social Psychology, 57 (3), 457-68.

Deutsch, Morton and Harold B. Gerard (1955), "A Study of Normative and Informational Social Influences upon Individual Judgment," Journal of Abnormal and Social Psychology, 51 (November), 624-36.

Douglas, Mary and Baron Isherwood (1978), The World of Goods: Towards an Anthropology of Consumption, New York: Norton.

Englis, Basil G. and Michael R. Solomon (1995), “To Be and Not to Be? Lifestyle Imagery, Reference Groups, and the Clustering of America," Journal of Advertising, 24 (Spring), 13-28.

Escalas, Jennifer E. and James R. Bettman (2003), "You Are What They Eat: The Influence of Reference Groups on Consumer Connections to Brands," Journal of Consumer Psychology, 13 (3), 339-48.

(2005), "Self-Construal, Reference Groups, and Brand Meaning," Journal of Consumer Research, 32 (December), 378-89.

Fromkin, Harold L. (1968), "Affective and Valuational Consequences of Self-Perceived Uniqueness Deprivation," unpublished doctoral dissertation, Psychology Department, The Ohio State University.

- (1970), "Effects of Experimentally Aroused Feelings of Indistinctiveness upon Valuation of Scarce and Novel Ex- 
periences," Journal of Personality and Social Psychology, 16 (3), 521-29.

Gladwell, Malcolm (2000), The Tipping Point: How Little Things Can Make a Big Difference, New York: Little, Brown.

Golder, Peter N. and Gerard J. Tellis (2004), "Going, Going, Gone: Cascades, Diffusion, and Turning Points of the Product Life Cycle," Marketing Science, 23 (2), 180-91.

Hebdige, Dick (1987), Subculture: The Meaning of Style, London: Routledge.

Holman, Rebecca H. (1981), "Product as Communication: A Fresh Appraisal of a Venerable Topic," in Review of Marketing, ed. Ben M. Eris and Kenneth J. Boering, Chicago: American Marketing Association, 106-19.

Katz, Daniel (1960), "The Functional Approach to the Study of Attitudes," Public Opinion Quarterly, 24 (2), 163-204.

Kelley, Harold H. (1973), "The Process of Causal Attribution," American Psychologist, 28 (February), 107-28.

Kernis, Michael H. (1984), "Need for Uniqueness, Self-Schemas, and Thought as Moderators of the False-Consensus Effect," Journal of Experimental Social Psychology, 20 (4), 350-62.

Kleine, Robert E., III, Susan S. Kleine, and Jerome B. Kernan (1993), "Mundane Consumption and the Self: A Social Identity Perspective," Journal of Consumer Psychology, 2 (3), 209-35.

Levy, Sidney J. (1959), "Symbols for Sale," Harvard Business Review, 33 (March-April), 117-24.

Lynn, Michael and Judy Harris (1997), "The Desire for Unique Consumer Products: A New Individual Differences Scale," Psychology and Marketing, 14 (September), 601-16.

McCracken, Grant (1988), Culture and Consumption: New Approaches to the Symbolic Character of Consumer Goods and Activities, Bloomington: Indiana University Press.

Moschis, George P. (1976), "Social Comparison and Informal Group Influence," Journal of Marketing Research, 13 (August), 237-44.

Muniz, Albert M. and Thomas C. O'Guinn (2001), "Brand Community," Journal of Consumer Research, 27 (March), 412-32.

Nail, Paul R., Geoff MacDonald, and David A. Levy (2000), "Proposal of a Four-Dimensional Model of Social Response," Psychological Bulletin, 126 (3), 454-70.

Park, C. Whan and V. Parker Lessig (1977), "Students and Housewives: Differences in Susceptibility to Reference Group Influence," Journal of Consumer Research, 4 (September), $102-10$.

Pronin, Emily, Jonah Berger, and Sarah Molouki (2007), “Alone in a Crowd of Sheep: Asymmetric Perceptions of Conformity and Their Roots in an Introspection Illusion," Journal of Personality and Social Psychology, 92 (4), 585-95.

Ratner, Rebecca K. and Barbara E. Kahn (2002), "The Impact of Private versus Public Consumption on Variety-Seeking Be- havior," Journal of Consumer Research, 29 (September), 246-58.

Rogers, Everett M. (1983), Diffusion of Innovations, New York: Free Press.

Shavitt, Sharon (1990), "The Role of Attitude Objects in Attitude Functions," Journal of Experimental Social Psychology, 26 (March), 124-48.

Shavitt, Sharon and Michelle R. Nelson (1999), "The Social Identity Function in Person Perception: Communicated Meanings of Product Preferences," in Why We Evaluate: Function of Attitudes, ed. Gregory R. Maio and James M. Olson, Mahwah, NJ: Erlbaum, 37-57.

Simmel, Georg (1904/1957), "Fashion," American Journal of Sociology, 62 (6), 541-48.

Snyder, Charles R. and Harold L. Fromkin (1977), "Abnormality as a Positive Characteristic: The Development and Validation of a Scale Measuring Need for Uniqueness," Journal of $A b$ normal Psychology, 86 (October), 518-27.

- (1980), Uniqueness, New York: Plenum.

Solomon, Michael R. (1988), "Mapping Product Constellations: A Social Categorization Approach to Symbolic Consumption," Psychology and Marketing, 5 (3), 233-58.

Solomon, Michael R. and Henry Assael (1987), "The Forest or the Trees? A Gestalt Approach to Symbolic Consumption," in Marketing and Semiotics: New Directions in the Study of Signs for Sale, ed. Jean Umiker-Sebeok, Berlin: Mouton de Gruyter, 189-218.

Stafford, James E. (1966), "Effects of Group Influence on Consumer Brand Preferences," Journal of Marketing Research, 3 (February), 68-75.

Thornton, Sarah (1996), Club Cultures: Music, Media, and Subcultural Capital, Middletown, CT: Wesleyan University Press.

Tian, Kelly T., William O. Bearden, and Gary L. Hunter (2001), "Consumers' Need for Uniqueness: Scale Development and Validation," Journal of Consumer Research, 28 (June), 50-66.

Tian, Kelly T. and Karyn McKenzie (2001), "The Long-Term Predictive Validity of Consumers' Need for Uniqueness Scale," Journal of Consumer Psychology, 10 (3), 171-93.

Vignoles, Vivian L., Xenia Chryssochoou, and Glynis M. Breakwell (2000), "The Distinctiveness Principle: Identity, Meaning, and the Bounds of Cultural Relativity," Personality and Social Psychology Review, 4 (4), 337-54.

Wernerfelt, Birger (1990), “Advertising Content When Brand Choice Is a Signal," Journal of Business, 63 (1), 91-98.

White, Kate and Darren Dahl (2006), "To Be or Not Be? The Influence of Dissociative Reference Groups on Consumer Preferences," Journal of Consumer Psychology, 16 (4), 404-14.

Wonacott, Peter (2004), “China's Buick Infatuation: The Stodgy American Auto Is a Pre-revolutionary Icon for Booming Middle Class," Wall Street Journal, July 22, B1. 